Revista Tecné, Episteme y Didaxis: TED. Año 2014, Número Extraordinario. ISSN Impreso: 0121-3814, ISSN web: 2323-0126

Memorias, Sexto Congreso Internacional sobre Formación de Profesores de Ciencias. 08 al 10 de octubre de 2014, Bogotá

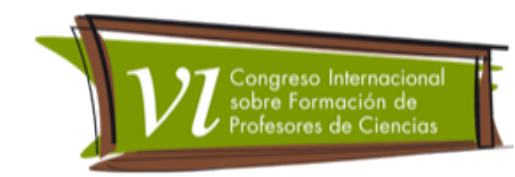

\title{
Aportes de la Estrategia DPS a la formación de docentes rurales en el área de ciencias naturales en Boyacá
}

Mesa Diana', Parra Sandra², Ramírez Fernando ${ }^{3}$

Categoría 1: Reflexiones y experiencias desde la innovación en el aula.

\section{Resumen}

El gobierno nacional propone dentro de su política educativa para el sector rural la implementación de la Estrategia Desarrollo Profesional Situado -DPS- que busca el mejoramiento de las prácticas de aula de los docentes rurales en el área de ciencias naturales, a partir de la implementación de secuencias didácticas prediseñadas que promueven el desarrollo de habilidades pensamiento científico en los estudiantes. La reflexión de esta experiencia didáctica busca analizar los aportes de la Estrategia DPS a los docentes rurales de algunos municipios del departamento de Boyacá, a partir de los hallazgos realizados por el tutor (profesional en educación encargado del acompañamiento en las sedes rurales focalizadas).

\section{Palabras clave}

Estrategia DPS, prácticas de aula, ciencias naturales, indagación, secuencia didáctica.

\section{Introducción}

\section{Estrategia Desarrollo Profesional Situado (DPS)}

"Desarrollo profesional situado se puede definir como el aprendizaje realizado en contextos auténticos, en torno a las problemáticas específicas de enseñanza de temas específicos en el aula, donde los aprendices participan en comunidades de práctica" (Abell et al., 2009, J. Brown, Collings, \& Duguid, 1989, Putman \&

\footnotetext{
1 Universidad Pedagógica y Tecnológica de Colombia -UPTC-. Correo: dianamesauptc@gmail.com

2 Universidad Pedagógica y Tecnológica de Colombia -UPTC-. Correo: samipabo30@hotmail.com

3 Universidad Pedagógica y Tecnológica de Colombia -UPTC-. Correo: josefercho@hotmail.com
} 
Revista Tecné, Episteme y Didaxis: TED. Año 2014, Número Extraordinario. ISSN Impreso: 0121-3814, ISSN web: 2323-0126

Memorias, Sexto Congreso Internacional sobre Formación de Profesores de Ciencias. 08 al 10 de octubre de 2014, Bogotá

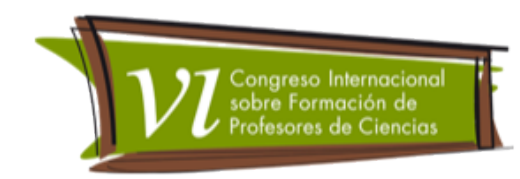

Borko, 2000). Esta metodología la adopta el Ministerio de Educación Nacional de Colombia -MEN-, con el propósito de promover el desarrollo de competencias en los estudiantes y la transformación de las prácticas de aula, para con ello cerrar la brecha e inequidad existente entre la educación rural y urbana (MEN, 2013).

"La Estrategia DPS promueve cambios significativos en las prácticas de aula enfocados en las áreas de ciencias naturales, matemáticas y la temática transversal de competencias ciudadanas" (MEN, 2013). En esta comunicación, se presenta los hallazgos relacionados exclusivamente con los procesos adelantados en el área de ciencias naturales en los municipios de Zetaquira, Berbeo, La Uvita y Paéz del departamento de Boyacá.

El acompañamiento a los docentes se realiza a través de actividades como: talleres de formación, visitas de observación de desempeños en el aula, construcción de portafolios y participación en círculos de estudio.

\section{Secuencias didácticas para la enseñanza de las ciencias naturales}

El diseño de las secuencias didácticas fue promovido por el Equipo Líder del Ministerio de Educación Nacional de acuerdo a el área (ciencias naturales, matemáticas y competencias ciudadanas), dichas secuencias fueron estructuradas teniendo en cuenta los diferentes niveles de formación académica, además proponen una sola temática para cada grado la cual se articula con los Estándares Básicos de Competencias según el área.

Las secuencias didácticas de ciencias naturales fueron elaboradas a partir del enfoque de enseñanza por indagación, un abordaje que se inscribe dentro de la línea constructivista del aprendizaje activo y bajo la guía del docente posiciona a los estudiantes como activos generadores de conocimiento escolar (Bybee et al, 2005, citado por Furman 2012).

Para materializar estas acciones de pensamiento y producción, relacionadas con el proceso de construcción de pensamiento científico.

Las secuencias parten de una pregunta central, cuya formulación pueda generar interés de los estudiantes, movilizar sus conocimientos previos, centrar la atención en la temática que se quiere abordar y por supuesto, promover la indagación. De la pregunta central se desprenden siete preguntas guía que tienen el propósito conducir gradualmente a los estudiantes en la construcción de saberes (saber 
Revista Tecné, Episteme y Didaxis: TED. Año 2014, Número Extraordinario. ISSN Impreso: 0121-3814, ISSN web: 2323-0126

Memorias, Sexto Congreso Internacional sobre Formación de Profesores de Ciencias. 08 al 10 de octubre de 2014, Bogotá

qué, saber cómo, saber para qué) que se conjugan para construir respuestas más completas (MEN, 2013). Ver figura 1.

En cada sesión los estudiantes tendrán momentos de exploración, formulación de preguntas, diseño y puesta en práctica de actividades experimentales, búsqueda de información, análisis de las experiencias, conceptualización, aplicación y puesta en común del proceso en diferentes momentos. "Así semana a semana, además de permitirles responder a la pregunta guía, van adquiriendo elementos conceptuales que además de ayudarles a comprender los diferentes fenómenos estudiados, promueven el desarrollo del pensamiento científico" (MEN, 2013).

\section{Objetivos de la experiencia desde el rol de tutor de la estrategia DPS.}

A continuación se mencionan los objetivos planteados desde el equipo de tutores respecto a la experiencia didáctica de implementación de la Estrategia DPS en los municipios de Boyacá.

\section{Objetivo general}

Analizar los aportes de la Estrategia DPS a los docentes rurales de algunos municipios del departamento de Boyacá, a partir de los hallazgos realizados por el tutor.

\section{Objetivos específicos}

- Caracterizar las prácticas de aula teniendo como guía la metodología propuesta en las secuencias didácticas prediseñadas.

- Identificar aciertos y dificultades de las actividades propuestas desde la Estrategia.

- Evaluar la metodología propuestas para la formación docente en el marco de la Estrategia DPS

\section{Instrumentos de recolección de información}

- Formatos de observación de clase (propuesto por el MEN)

- Entrevistas semi-estructuradas

- Formatos de evaluación de las jornadas

- Análisis del discurso 
Revista Tecné, Episteme y Didaxis: TED. Año 2014, Número Extraordinario. ISSN Impreso: 0121-3814, ISSN web: 2323-0126

Memorias, Sexto Congreso Internacional sobre Formación de Profesores de Ciencias. 08 al 10 de octubre de 2014, Bogotá

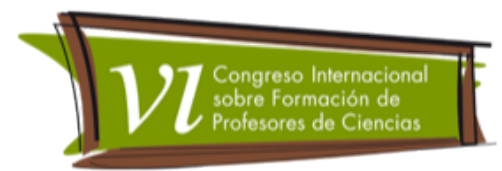

\section{Desarrollo}

Los resultados parciales obtenidos en Zetaquira, Berbeo, La Uvita y Paéz del departamento de Boyacá, en la experiencia desde el rol de tutor de la estrategia DPS se describen a continuación. Esta información se ha obtenido por medio del análisis de los formatos de observación de clase (propuesto por el MEN), formatos de evaluación de las jornadas y análisis del discurso.

A nivel general la información compilada se ha organizado en un listado de aciertos y debilidades, de acuerdo al tipo de actividad de acompañamiento que se ha desarrollado como talleres, visitas, portafolios y círculos de estudio, por parte del tutor a los docentes de sedes rurales focalizadas.

Tabla 1. Aciertos y debilidades según la actividad propuesta en la Estrategia DPS.

\begin{tabular}{|c|c|c|c|}
\hline \multicolumn{2}{|c|}{ Actividad } & Aciertos & Debilidades \\
\hline \multicolumn{2}{|c|}{ Talleres de formación } & $\begin{array}{l}\text { Fortalecen la apropiación } \\
\text { conceptual de elementos de la } \\
\text { enseñanza por indagación y los } \\
\text { pilares de transformación de las } \\
\text { prácticas de aula. } \\
\text { Brinda espacio para reconocer } \\
\text { algunos obstáculos que tienen } \\
\text { los estudiantes a la hora de } \\
\text { aprender. }\end{array}$ & $\begin{array}{l}\text { Se evidencia en los docentes } \\
\text { dificultad en la definición de } \\
\text { objetivos de aprendizaje que } \\
\text { sean observables y evaluables } \\
\text { desde un marco de } \\
\text { desempeños. } \\
\text { La gestión de espacios para la } \\
\text { realización de esta actividad } \\
\text { en varias IE no es dado por el } \\
\text { directivo docente. }\end{array}$ \\
\hline \multirow[t]{2}{*}{$\begin{array}{l}\text { Visitas de } \\
\text { observación }\end{array}$} & $\begin{array}{l}\text { Secuencias } \\
\text { didácticas }\end{array}$ & 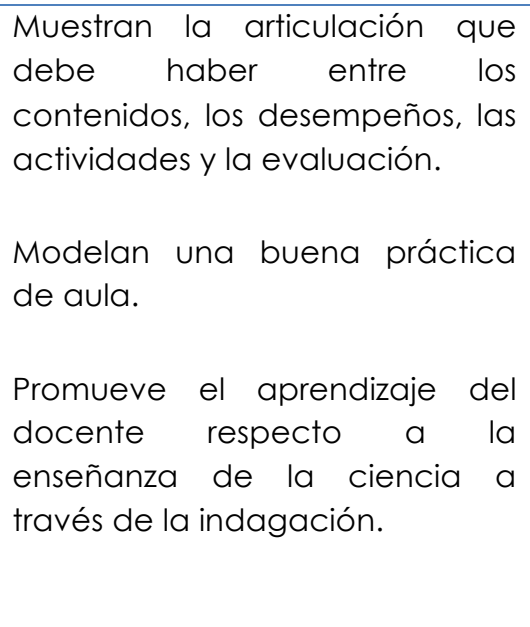 & $\begin{array}{l}\text { Proponen materiales de difícil } \\
\text { consecución debido a la } \\
\text { ubicación rural de las escuelas. } \\
\text { Son tomadas por muchos } \\
\text { docentes de manera muy } \\
\text { literal, lo que les impide hacer } \\
\text { una verdadera apropiación de } \\
\text { la metodología. } \\
\text { Dado que vienen propuestas } \\
\text { para desarrollar por grado, } \\
\text { existen dificultades en escuelas } \\
\text { multigrado. }\end{array}$ \\
\hline & $\begin{array}{l}\text { Planeación } \\
\text { de la clase }\end{array}$ & $\begin{array}{l}\text { Permite hacer una revisión de la } \\
\text { coherencia entre los contenidos, } \\
\text { desempeños, actividades (tanto }\end{array}$ & $\begin{array}{lll}\text { Los docentes no } & \text { especifican } \\
\text { claramente los } & \text { conceptos, } \\
\text { desempeños } & \text { esperados, }\end{array}$ \\
\hline
\end{tabular}


Revista Tecné, Episteme y Didaxis: TED. Año 2014, Número Extraordinario. ISSN Impreso: 0121-3814, ISSN web: 2323-0126

Memorias, Sexto Congreso Internacional sobre Formación de Profesores de Ciencias. 08 al 10 de octubre de 2014, Bogotá

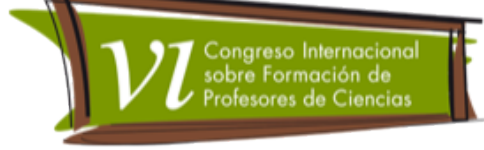

\begin{tabular}{|c|c|c|}
\hline & $\begin{array}{l}\text { del docente como del } \\
\text { estudiante) y las estrategias de } \\
\text { evaluación. } \\
\text { El docente lleva su planeación } \\
\text { escrita. }\end{array}$ & $\begin{array}{l}\text { actividades a realizar por parte } \\
\text { del docente y estudiantes } \\
\text { En algunos casos, la } \\
\text { planeación es vista como un } \\
\text { requisito de la Estrategia y no } \\
\text { como una herramienta que } \\
\text { permita cambiar el } \\
\text { planteamiento de la clase. }\end{array}$ \\
\hline $\begin{array}{l}\text { Ejecución } \\
\text { de la clase }\end{array}$ & $\begin{array}{l}\text { Se evidencia que los docentes } \\
\text { poseen dominio sobre las } \\
\text { temáticas, sin embargo, existen } \\
\text { varios vacíos conceptuales. } \\
\text { Los docentes intentan organizar } \\
\text { los estudiantes en grupos de } \\
\text { trabajo (Aprendizaje } \\
\text { cooperativo). } \\
\text { El docente vivencia los } \\
\text { beneficios de la enseñanza por } \\
\text { indagación. }\end{array}$ & $\begin{array}{l}\text { Respecto al Aprendizaje } \\
\text { cooperativo, la asignación de } \\
\text { roles es la actividad menos } \\
\text { implementada. } \\
\text { Se observa parte del tiempo } \\
\text { que usa el docente para el } \\
\text { desarrollo de las actividades es } \\
\text { tiempo muerto (no productivo). } \\
\text { Las indicaciones de los } \\
\text { procedimientos dadas por el } \\
\text { docente no son claras, ya que } \\
\text { los estudiantes no comprenden } \\
\text { con facilidad. }\end{array}$ \\
\hline $\begin{array}{l}\text { Evaluación } \\
\text { de la clase }\end{array}$ & $\begin{array}{lrr}\begin{array}{l}\text { Ejecutan actividades } \\
\text { evaluación }\end{array} & \text { (formativa } \\
\text { sumativa) que proponen las } \\
\text { secuencias didácticas. }\end{array}$ & $\begin{array}{l}\text { Dificultades con la puesta en } \\
\text { marcha en el aula instrumentos } \\
\text { o acciones de evaluación para } \\
\text { el aprendizaje. }\end{array}$ \\
\hline & $\begin{array}{l}\text { Los docentes reconocen los } \\
\text { aprendizajes de los estudiantes } \\
\text { como de ellos mismos. } \\
\text { Revisar las actividades de } \\
\text { evaluación que diariamente los } \\
\text { docentes vienen } \\
\text { implementando en el área de } \\
\text { ciencias naturales. }\end{array}$ & $\begin{array}{l}\text { Los docentes formulan } \\
\text { frecuentemente preguntas } \\
\text { CERRADAS que no promueven } \\
\text { un proceso de reflexión sobre } \\
\text { los saberes y procedimientos } \\
\text { de los estudiantes. } \\
\text { Ausencia de acciones para } \\
\text { realimentar los saberes de los } \\
\text { estudiantes. }\end{array}$ \\
\hline Construcción de portafolios & $\begin{array}{l}\text { Permite evaluar tanto el proceso } \\
\text { de aprendizaje del docente } \\
\text { como el logro de las metas } \\
\text { propuestas. } \\
\text { Requiere un trabajo de reflexión } \\
\text { sobre la práctica docente. }\end{array}$ & $\begin{array}{l}\text { Muchos docentes han tenido } \\
\text { dificultades con la } \\
\text { estructuración del portafolio } \\
\text { debido a que no tienen el } \\
\text { hábito de escribir. } \\
\text { Los docentes tienden a }\end{array}$ \\
\hline
\end{tabular}


Revista Tecné, Episteme y Didaxis: TED. Año 2014, Número Extraordinario. ISSN Impreso: 0121-3814, ISSN web: 2323-0126

Memorias, Sexto Congreso Internacional sobre Formación de Profesores de Ciencias. 08 al 10 de octubre de 2014, Bogotá

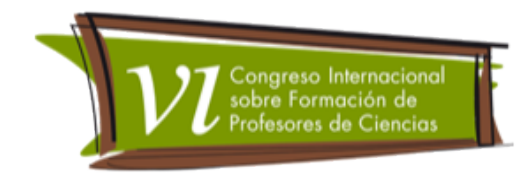

\begin{tabular}{|c|c|c|}
\hline & & $\begin{array}{l}\text { confundirlo con una carpeta } \\
\text { de trabajos o como evidencia } \\
\text { exclusiva de la Estrategia. }\end{array}$ \\
\hline $\begin{array}{l}\text { Participación en círculos de } \\
\text { estudio }\end{array}$ & $\begin{array}{l}\text { Permite la socialización de } \\
\text { experiencias en la } \\
\text { implementación de la propuesta } \\
\text { de enseñanza de las ciencias } \\
\text { naturales. } \\
\text { Fomentan el dialogo constante } \\
\text { entre docentes y directivos } \\
\text { docentes. }\end{array}$ & $\begin{array}{l}\text { Dificultades con la } \\
\text { coordinación y liderazgo del } \\
\text { directivo docente en las } \\
\text { sesiones de realización. } \\
\text { Grandes distancias entre las } \\
\text { sedes. }\end{array}$ \\
\hline
\end{tabular}

Fuente: Mesa, D.; Parra, S. \& Ramírez, F.

Así mismo, el proceso adelantado ha permitido dentro de su marco de evaluación reconocer variables indirectas que influyen en el óptimo desarrollo del proceso de formación docente en el marco de la Estrategia DPS, como:

- Los tutores: dado que varios de ellos no tienen perfil profesional en formación de ciencias naturales, sin embargo, deben ser competentes para orientar a un docente focalizado en los elementos de enseñanza para ciencias naturales.

- Cantidad de estudiantes en el aula (multigrado): los docentes que están bajo esta condición han mostrado indisposición en el momento de participar activamente en la Estrategia DPS, al no poder integrar a todos los estudiantes y romper con el esquema diario del aula de clase.

- Liderazgo del directivo docente: la generación o no de espacios de formación y socialización como talleres y círculos de estudio motiva o desmotiva el interés del docente en la participación de la Estrategia.

- Conectividad a internet del docente: mucha de las fuentes bibliográficas a las que tienen acceso los docentes están desactualizadas, sin embargo, dadas las distancias de ubicación de las escuelas rurales tampoco tienen acceso a internet.

\section{Reflexión final}

La apreciación del proceso de acompañamiento desde el rol de tutores Estrategia DPS permitió analizar los aciertos y debilidades de las actividades 
Revista Tecné, Episteme y Didaxis: TED. Año 2014, Número Extraordinario. ISSN Impreso: 0121-3814, ISSN web: 2323-0126

Memorias, Sexto Congreso Internacional sobre Formación de Profesores de Ciencias. 08 al 10 de octubre de 2014, Bogotá

propuestas en el marco de la enseñanza de las ciencias naturales, que deben ser revaluadas por los pares académicos del MEN, dado que el sentido el con que se han diseñado todos los instrumentos, secuencias y en general metodología no es el mismo con el que llegan a los docentes, así mismo, actividades como la construcción de portafolios y consolidación de círculos de estudio significan gran demanda de tiempo con poca productividad académica en la mayoría de los casos.

\section{Referencias bibliográficas}

Abell, Sandra, Rogers, Meridiath, Deborah, Hanuscin, \& Gagnon, Mark. (2009). preparing the next generation of science teacher educators: a model for developing PCK for teaching science teachers. Journal of science teacher education - Springer, 20.

Banco Mundial- Ministerio de Educación Nacional. (2011). Reporte del uso del tiempo en el aula: evidencia para Colombia utilizando el método de observación de Stallings. Washington D.C.: The world Bank.

Furman, Melina. (2009). Planificación inversa: Expedición ciencia argentina.

Furman, Melina. (2012). Programa de Educación Rural - PER: Orientaciones Técnicas para la producción de secuencias didácticas para un desarrollo profesional situado en las áreas de matemáticas y ciencias. Bogotá: Ministerio de Educación Nacional de Colombia.

MEN. (1998). Lineamientos Curriculares Ciencias Naturales y Educación Ambiental. Ministerio de Educación Nacional de Colombia.

MEN. (2004). Estándares Básicos de Competencias en Ciencias Naturales y Ciencias Sociales. Ministerio de Educación Nacional de Colombia.

MEN. (2013). Programa fortalecimiento de la cobertura con calidad para el sector rural, Fase II: Estructura y trayectoria para el desarrollo profesional situado (DPS) en ciencias y matemáticas. Ministerio de Educación Nacional de Colombia.

MEN. (2013). Secuencias Didácticas en Ciencias Naturales para Educación Básica Primaria; Secundaria; Media. Ministerio de Educación Nacional de Colombia. 